\title{
Reply to Machery: Against the argument from citation
}

\author{
Jordan David Thomas Walters \\ jordan.walters@mail.mcgill.ca
}

This is an Accepted Manuscript of an article published by Taylor \& Francis in the International Journal of Philosophical Studies on March 13th, 2021, available online: https: / wmm.tandfonline.com/ doil full/ 10.1080/09672559.2021.1898440

In a recent paper published in this journal, Hughes (2019) has argued that Machery's (2017) Dogmatism Argument is self-defeating. Machery's (2019) reply involves giving the Dogmatism Argument an inductive basis, rather than a philosophical basis. That is, he argues that the most plausible contenders in the epistemology of disagreement all support the Dogmatism Argument; and thus, it is likely that the Dogmatism Argument is true, which gives us reason to accept it. However, Machery's inductive argument defines the leading views in terms of their citation counts. But there is no necessary connection between citation counts and truth; it is a truism that many highly cited papers over the past century have turned out to contain false arguments. This inductive information should lead Machery to revise his argument; what Machery (2019) owes—but has failed to provide—is a positive argument for ruling out another plausible contender that Hughes (2019) raises. Without such an account, Machery's inductive case for the Dogmatism Argument fails.

Let's begin by getting Machery's (2017) dogmatism argument on the table :

\section{DOGMATISM ARGUMENT}

1. Most of the philosophical cases examined by experimental philosophers elicit disagreement.

2. This disagreement takes place among epistemic peers.

3. If most of the philosophical cases examined by philosophers elicit disagreement among peers, then most philosophical cases would plausibly elicit disagreement among peers.

4. If epistemic peers are likely to disagree about a philosophical case, they ought to suspend judgment about it.

5. Hence, expect for those philosophical cases known not to elicit disagreement among peers, philosophers ought to suspend judgment about situations described by philosophical cases (Machery 2017: 127).

As Hughes (2019) has pointed out, the dogmatism argument seems to be self-defeating because it relies on premises arrived at through the method of cases. Hughes writes: 
Rejecting dogmatism requires adopting a position on the epistemology of disagreement. Anti-dogmatic views in the epistemology of disagreement were motivated by judgments about precisely the kinds of cases that Machery would have banished from philosophical theorizing. Since, according to Machery, we shouldn't be relying on such judgments, insofar as we accept his view we lack justification for rejecting dogmatism (Hughes 2019: 592). ${ }^{1}$

In response to Hughes (2019), Machery (2019) has claimed that he can still support premise 4 of the dogmatism argument without appealing to cases. To do this, he relies on a simple disjunctive argument of the following form: "Suppose that either $p$ or $q$ is the case, and that both propositions entail $r$, one is entitled to accept $r$ if one can show that both propositions entail $r$, even if one is unable to know whether $p$ or $q$ is the case.” (Machery 2019: 616). Reconstructing Machery's argument against Hughes (2019: 592) yields the following:

1. Suppose that either $p$ or $q$ is the case, where $p$ and $q$ are "plausible contender[s] (or a variant thereof) for getting it right about peer disagreement" (Machery 2019: 616).

2. Both $p$ and $q$ entail premise 4 of the dogmatism argument.

3. Therefore, "it is thus likely that Premise 4 of Dogmatism is right, which gives us license for accepting it." (Machery 2019: 617).

Machery's argument trades on a narrow selection of what "plausible contenders" exist in the literature on the epistemology of disagreement. While it may be true that most views lead to premise 4 of the dogmatism argument, it is not the case that all views do. For instance, Hughes (2019: 595) cites Hawthorne and Srinivasan (2013), who develop a knowledge-centric epistemology of disagreement. Hughes summarizes their view as follows:

The Knowledge Disagreement Norm (KDN): In a case of disagreement about whether P, where S believes that $\mathrm{P}$ and $\mathrm{H}$ believes that not-P:

(i) S ought to trust $\mathrm{H}$ and believe that not-P iff were $\mathrm{S}$ to trust $\mathrm{H}$, this would result in $\mathrm{S}$ 's knowing not-P

${ }^{1}$ As cited in Machery (2019: 616). 
(ii) $\mathrm{S}$ ought to dismiss $\mathrm{H}$ and continue to believe that $\mathrm{P}$ iff were $\mathrm{S}$ to stick to her guns this would result in S's knowing $\mathrm{P}$, and

(iii) In all other cases, S ought to suspend judgement about whether P (Hughes 2019: 595).

Following this, Hughes (2019) claims that we can combine the KDN with an anti-defeatist approach to knowledge. ${ }^{2}$ Hughes writes:

According to this view S may continue to know that $\mathrm{P}$, even in the face of disagreement, provided that S's belief was formed (and is maintained) on the basis of a safe method. When we combine these two theses, we get the result that one can know that $\mathrm{P}$ even if one's epistemic peers disagree, and, if one does know that $\mathrm{P}$, one ought to stick to one's guns and continue to believe that P" (Hughes 2019: 595).

It strikes me as strange that Machery (2019) would fail to include Hawthorne and Srinivasan's (2013) argument as a "plausible contender" in the epistemology of disagreement; or at least if there is a problem with the argument, Machery (2019) does not tell us what it is. Instead, Machery makes the case for other leading views on the basis of citation counts. I quote him at length:

People are bound to disagree about which philosophical articles count as a major contribution, and perhaps Hawthorne and Srinivasan (2013) does count as a major contribution to the epistemology of peer disagreement in some respects. Although it is sometimes considered crass to mention citation counts, particularly among philosophers, surely they say something about how influential and how frequently discussed a paper is. Hawthorne and Srinivasan (2013) does not fare too poorly by this measure: In philosophy, 43 citations (as of 13 June 2019) isn't a figure to be ashamed of, but this number pales in comparison to those of the classics in this area of philosophy, which have articulated what I took (and still take) to be the major views about peer disagreement: Elga (2007) has been cited 659 times; Kelly (2010), 431 times, etc (Machery 2019: 617).

Let's call this the argument from citation counts. It is unclear (and perhaps crass) as to why Machery would make reference to citation counts and not the content of Hawthorne and Srinivasan's (2013) argument

\footnotetext{
${ }^{2}$ Hughes cites Lasonen-Aarino (2010).
} 
in determining whether it a "plausible contender" in the epistemology of disagreement. As Machery himself points out, citation counts only tell us "how frequently discussed a paper is" (Machery 2019: 617). It is a mere descriptive fact that some article $x$ is cited more than $y$; and learning this descriptive fact will tell us nothing about whether the argument contained in $x$ is better than the argument contained in contained in $y$. And without a positive argument against Hawthorne and Srinivasan's (2013) argument, Machery is forced to modify his argument against Hughes, thus yielding the following:

1. Suppose that either $p$ or $q$ or $x$ is the case, where $p$ and $q$ and $x$ are "plausible contender[s] (or a variant thereof) for getting it right about peer disagreement” (Machery 2019: 616).

2. $p$ and $q$ entail premise 4 of the dogmatism argument, whereas $x$ entails its negation.

3. Therefore, "it is thus likely that Premise 4 of Dogmatism is right, which gives us license for accepting it.” (Machery 2019: 617).

The problem with the modified argument is that the conclusion does not follow from the premises, for we have added a third contender $x$ to the first premise. If Machery (2019) wants to support premise 4 of the dogmatism argument on inductive grounds — rather than philosophical grounds — then he will have to find a way to show that Hawthorne and Srinivasan's (2013) argument is not a plausible contender in the epistemology of disagreement - and the argument from citation counts, as I have shown, fails. $^{3}$

\section{References}

Elga, Adam. 2007. "Reflection and Disagreement." Noûs 41 (3) 478-502.

Hawthorne, John, and Srinivasan, Amia. 2013. "Disagreement without Transparency: Some Bleak

Thoughts." In The Epistemology of Disagreement, edited by David Christensen and Jennifer Lackey, 9-31. Oxford: Oxford University Press.

Hughes, Nick. 2019. "Disagreement, Dogmatism, and the Bounds of Philosophy." International Journal of Philosophical Studies 27 (4): 591-96.

Kelly, Thomas. 2010. "Peer Disagreement and Higher Order Evidence." In Social Epistemology:

Essential Readings, edited by Alvin I Goldman and Dennis Whitcomb, 183-217. Oxford: Oxford

University Press.

Lasonen-Aarino, Maria. 2010. “Unreasonable Knowledge.” Philosophical Perspectives, no. 24: 1-21. Machery, Edouard. 2017. Philosophy Within Its Proper Bounds. New York: Oxford University Press.

- 2019. "Response to Akagi, Hughes, and Springle." International Journal of Philosophical Studies 27 (4): 608-23.

\footnotetext{
${ }^{3}$ An anonymous referee has insightfully noted that Machery will likely have to rely on the method of cases to demonstrate that Hawthorne and Srinivasan's (2013) view is not a plausible contender in the epistemology of disagreement. But the Dogmatism Argument rules this out. Hence, the self-defeating objection rears its head once again.
} 